\title{
Simulating streamflow response to climate scenarios in central Canada using a simple statistical downscaling method
}

\author{
Woonsup Choi ${ }^{1, *}$, Peter F. Rasmussen ${ }^{2}$, Adam R. Moore ${ }^{2}$, Sung Joon Kim² \\ ${ }^{1}$ Department of Geography, University of Wisconsin-Milwaukee, PO Box 413, Milwaukee, Wisconsin 53201, USA \\ ${ }^{2}$ Department of Civil Engineering, University of Manitoba, 15 Gillson Street, Winnipeg, Manitoba R3T 5V6, Canada
}

\begin{abstract}
Despite the importance of surface water in Manitoba, Canada, there has been relatively little investigation of the impact of climate change on the hydrology of the province. This study examines streamflow characteristics in northern Manitoba basins (Taylor and Burntwood River basins) under climate scenarios generated by global climate models (GCM) from 2 agencies (the UK Hadley Centre and the Canadian Centre for Climate Modelling and Analysis). The hydrological model SLURP (Semi-distributed Land Use-based Runoff Processes) was run with perturbed meteorological data based on the GCM simulations under 2 greenhouse gas emission scenarios (A2 and B2) for 2 future periods (2041-2070 and 2071-2099). A method to incorporate the changed variability in future temperature and precipitation to the climate scenarios was also tested. All scenarios project wetter and warmer climates, and simulation results show that the mean annual runoff is likely to increase in every scenario. The largest seasonal increase occurs in late spring and the least in winter and summer. The daily flow exceeded by $80 \%$ of the total records is also projected to substantially increase, resulting in much fewer days with extreme low flow compared to the control period. Results indicate that the combination of a hydrological model with simple GCM-based scenarios can produce results comparable to those obtained from regional climate modelling. Explicit incorporation of changed variability in climate scenarios results in higher runoff than consideration of only changes in means.
\end{abstract}

KEY WORDS: Climate change impact $\cdot$ Runoff $\cdot$ Statistical downscaling $\cdot$ SLURP $\cdot$ Manitoba Resale or republication not permitted without written consent of the publisher

\section{INTRODUCTION}

The Province of Manitoba, Canada, is rich in water resources and, of its total energy consumption, approximately $98 \%$ is produced at hydroelectric generating stations located on the Nelson, Saskatchewan, and Winnipeg Rivers (The Manitoba Hydro-Electric Board 2006). For obvious reasons, Manitoba Hydro, the sole energy provider in Manitoba, has a vested interest in understanding climate change impact on water yield in the basins contributing flow to their generating stations. More generally, climate change has become a significant concern in Manitoba as it is likely to have an impact on many other sectors, including agriculture, transportation (e.g. winter roads), wildlife, and tourism.
The main rivers of interest to Manitoba Hydro flow northward or northeastward, passing through the boreal forest biome and eventually flowing into Hudson Bay. Despite its importance, the hydrology of northern Manitoba has not been widely studied. Partly due to its vastness and remoteness, only a few physically based hydrological models have been applied in the region. St. Laurent \& Valeo (2007) modified and applied the hydrological model SLURP (Semi-distributed Land Use-based Runoff Processes) to the Burntwood and the Taylor River basins; the same basins were also modeled by Choi et al. (2009) using the North American Regional Reanalysis data (Mesinger et al. 2006) for calibration. However, neither of these papers addressed the potential impacts of climate change on the hydrological characteristics of the basins. Since global cli- 
mate models (GCMs) consistently project mean temperature increases of several degrees in northern Manitoba by the second half of the 21st century (Boer et al. 2000, Johns et al. 2003), it is imperative to assess the related effects on water resources.

Few studies have addressed the effect of past or potential climate change on the hydrological cycle in Manitoba. This is in contrast to other areas in Canada where extensive studies have been undertaken, including British Columbia (see Merritt et al. 2006 for a review on B.C. studies), Ontario (e.g. Cunderlik \& Simonovic 2005), and Quebec (e.g. Roy et al. 2001). Westmacott \& Burn (1997) and Yulianti \& Burn (1998) investigated links between climatic warming and hydrologic characteristics of river basins in the Canadian Prairies, including portions of Alberta, Saskatchewan, and Manitoba, by analysing past streamflow and temperature data. While they discovered a clear relationship between stream flow and temperature, they did not provide explicit projection of future climatic and hydrological characteristics. Sushama et al. (2006) investigated the Churchill and the Nelson River basins using 2 different versions of the Canadian Regional Climate Model (v3.6 and v3.7). Both of these rivers flow through Manitoba to Hudson Bay. The simulations consistently indicate that runoff will increase and that there will be fewer days with extreme low flows for the 2 basins.

Unfortunately, the availability of regional climate model (RCM) scenarios is somewhat limited; thus, RCMs may not be the best tool for practical assessment of climate change at the regional scale. As pointed out by Fowler et al. (2007) and others, a massive computational effort is required to produce RCM data for hydrologic modelling; thus, hydrologists are typically left with a limited range of RCM scenarios that are published by different climate research centres. For this reason, simpler statistical downscaling methods are often used in climate change studies.

The present study investigates the impact of climate change on 2 watersheds in northern Manitoba using a simple statistical downscaling method. More specifically, the study examines the sensitivity of the Burntwood and the Taylor River watersheds to GCM-based climate scenarios using the physically based hydrological model SLURP. The key objective is to investigate the projected changes in basin runoff and compare results with those obtained by Sushama et al. (2006) using a RCM-based approach.

\section{STUDY AREA}

The Taylor and the Burntwood River basins, which are located inside the greater Nelson River basin in northern Manitoba, were chosen for the case study. The 2 basins were modelled by St. Laurent \& Valeo (2007) and their calibrated models were used in the present study. The location of the basins is shown in Fig. 1 and information about the hydrometric stations and the weather stations is given in Table 1. The drainage areas upstream of each hydrometric station are 886 and $5810 \mathrm{~km}^{2}$ for Taylor and Burntwood, respectively. Measured streamflow data from the hydrometric stations were used for model calibration. The median annual flow is $5.10 \mathrm{~m}^{3} \mathrm{~s}^{-1}$ for Taylor and $20.5 \mathrm{~m}^{3} \mathrm{~s}^{-1}$ for Burntwood.

The region is characterized by a humid and cold climate with short and cool summers. In Thompson during 1971-2000, the mean monthly temperature did not rise above $20^{\circ} \mathrm{C}$ in any month and stayed below 0 from November through April. Precipitation was high during summer and low during winter, with a mean annual total of $517 \mathrm{~mm}$, of which roughly $2 / 3$ fell as rain. Snowfall was observed in every calendar month except in July. In The Pas, $\sim 300 \mathrm{~km}$ southwest of Thompson, mean annual precipitation was $443 \mathrm{~mm}$ and $73 \%$ of precipitation fell as rain during the same period. Mean monthly temperatures in The Pas were generally a few degrees higher than in Thompson. In both basins, spring snowmelt produce high runoff in May, and summer runoff is generally sustained by base flow and occasional storms. During the $30 \mathrm{yr}$ period, mean annual temperature shows a slightly increasing trend and annual total precipitation shows a

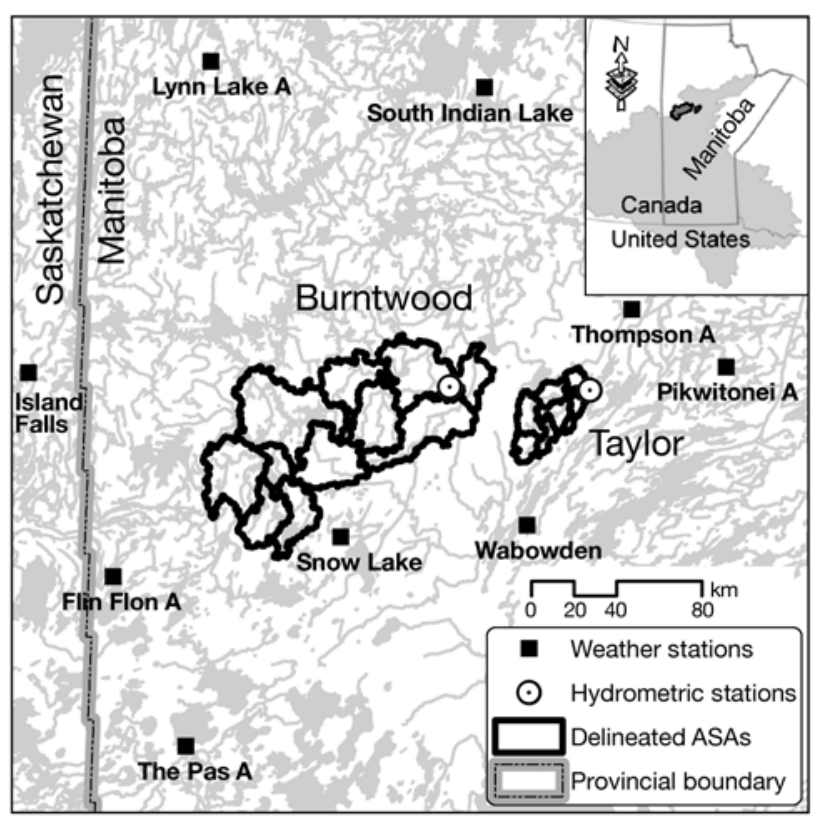

Fig. 1. Delineated aggregated simulation areas (ASAs) for the Taylor and the Burntwood River basins, along with hydrometric stations $(\odot)$, weather stations $(\boldsymbol{\square})$, and the boundary of the Nelson River basin (light grey, inset map) 
slightly decreasing trend, but none of these are statistically significant $(\alpha=0.05)$ according to the MannKendall nonparametric test for trend. Mean annual stream flow shows no particular trend either.

The basins have relatively little topographic relief, as the elevation of the weather stations indicates (Table 1). They lie within the Canadian shield and the terrain can be described as hummocky, with bogs and fens appearing in low lying areas (Metcalfe \& Buttle 1999). Muskeg is one of the dominant types of land cover, along with coniferous forest. It is characterised by low-growing bushes, mosses, and grasses growing on water-saturated soil (de Blij \& Muller 1996).

\section{THE HYDROLOGICAL MODEL SLURP}

\subsection{Model overview}

The hydrological model SLURP was chosen for this study. SLURP is a semi-distributed, basin-scale hydrological model that simulates runoff based on daily weather input data (precipitation, mean temperature, relative humidity, and bright sunshine hours) and physiographic data (land cover and elevation). The model has been found to be robust and suitable for the northern environment at various geographical scales (Leenders \& Woo 2002). It has been applied to several Canadian catchments other than those in Manitoba, including the Liard basin (van der Linden \& Woo 2003, Thorne \& Woo 2006, Woo \& Thorne 2006), a prairie wetland in Saskatchewan (Su et al. 2000), the Rocky Mountains (Kite 1993), and the Mackenzie River basin (Kite 1995, Haberlandt \& Kite 1998). Kite (2000) provides detailed information on SLURP, but a brief description is given here.

In SLURP, a basin is divided into a number of aggregated simulation areas (ASAs). An ASA contains cer- tain land cover types, and the vertical water balance is calculated for each land cover in each ASA. Then water is routed to the outlet of each ASA and further on to the outlet of the basin. An ASA has information on the percentage of each land cover type, but not on their location within the ASA.

SLURP simulates the vertical water balance with 4 storage tanks for each land cover in each ASA: canopy store, snow store, fast store, and slow store. Precipitation is provided as input of water to ASAs, and fluxes such as interception, sublimation, evapotranspiration (ET), surface runoff, interflow, and base flow are calculated from the storage tanks. Four different methods for estimating ET are available in SLURP: (1) the complementary relationship areal evaporation model, (2) the Granger method, (3) the Spittlehouse method, and (4) the FAO version of the Penman-Monteith algorithm (see Kite 2000 for more information on each method). The Spittlehouse method (Spittlehouse 1989) was selected for this study, based on the recommendations of Barr et al. (1997) who found that it is more physically sound and results between simulated and observed stream flow are in better agreement. Water in the snow store is depleted by snowmelt, which is calculated by either a simple degree-day approach or a simplified energy budget method. The degree-day approach was selected for this study because of its simplicity and robustness. The algorithm was modified by St. Laurent \& Valeo (2007) to accommodate the delayed response of thick snowpack to the rising temperature.

\subsection{Data and model setup}

The SLURP model was set up for the Taylor and the Burntwood River basins by St. Laurent \& Valeo (2007) using digital elevation data from the National Aeronautics and Space Administration Shuttle Radar Topo-

Table 1. Environment Canada weather stations and Water Survey of Canada hydrometric stations in the study area. P: precipitation, T: temperature, RH: relative humidity, and BSH: bright sunshine hours. ${ }^{*}$ Not shown in Fig. 1

\begin{tabular}{|c|c|c|c|c|c|}
\hline Station name & Station ID & Lat / long & $\begin{array}{c}\text { Elevation } \\
\text { (m a.s.l.) }\end{array}$ & Record period & Data obtained \\
\hline Taylor River near Thompson & 05 TG005 & $55^{\circ} 29^{\prime} 20^{\prime \prime} \mathrm{N}, 98^{\circ} 11^{\prime} 10^{\prime \prime} \mathrm{W}$ & N/A & 1970-present & Stream flow \\
\hline Burntwood River above Leaf Rapids & 05TE002 & $55^{\circ} 30^{\prime} 00^{\prime \prime} \mathrm{N}, 99^{\circ} 13^{\prime} 20^{\prime \prime} \mathrm{W}$ & N/A & 1985-present & Stream flow \\
\hline Thompson A & 5062922 & $55^{\circ} 48^{\prime} \mathrm{N}, 97^{\circ} 52^{\prime} \mathrm{W}$ & 222.2 & 1967-present & $\mathrm{P}, \mathrm{T}, \mathrm{RH}, \mathrm{BSH}$ \\
\hline Snow Lake & 5062706 & $54^{\circ} 52^{\prime} \mathrm{N}, 100^{\circ} 1^{\prime} \mathrm{W}$ & 295.7 & 1983-1998 & $\mathrm{P}, \mathrm{T}$ \\
\hline Wabowden & 5063041 & $54^{\circ} 55^{\prime} \mathrm{N}, 98^{\circ} 39^{\prime} \mathrm{W}$ & 231.6 & $1982-2001$ & $\mathrm{P}, \mathrm{T}$ \\
\hline South Indian Lake A & 5062736 & $56^{\circ} 48^{\prime} \mathrm{N}, 98^{\circ} 54^{\prime} \mathrm{W}$ & 289.0 & 1989-1998 & $\mathrm{P}, \mathrm{T}$ \\
\hline Lynn Lake A & 5061646 & $56^{\circ} 51^{\prime} \mathrm{N}, 101^{\circ} 4^{\prime} \mathrm{W}$ & 356.6 & 1959-2005 & $\mathrm{P}, \mathrm{T}$ \\
\hline The Pas A & 5052880 & $53^{\circ} 58^{\prime} \mathrm{N}, 101^{\circ} 6^{\prime} \mathrm{W}$ & 270.4 & 1953-present & $\mathrm{P}, \mathrm{T}, \mathrm{RH}, \mathrm{BSH}$ \\
\hline Gillam $A^{*}$ & 5061001 & $56^{\circ} 21^{\prime} \mathrm{N}, 94^{\circ} 42^{\prime} \mathrm{W}$ & 145.1 & 1970-present & $\mathrm{P}, \mathrm{T}$ \\
\hline Pikwitonei A & 5062111 & $55^{\circ} 34^{\prime} \mathrm{N}, 97^{\circ} 10^{\prime} \mathrm{W}$ & 192.0 & $1987-1995$ & $\mathrm{P}, \mathrm{T}$ \\
\hline Flin Flon A & 5050960 & $54^{\circ} 40^{\prime} \mathrm{N}, 101^{\circ} 40^{\prime} \mathrm{W}$ & 303.9 & 1954-present & $\mathrm{P}, \mathrm{T}, \mathrm{RH}$ \\
\hline Island Falls & 4063560 & $55^{\circ} 31^{\prime} \mathrm{N}, 102^{\circ} 21^{\prime} \mathrm{W}$ & 299.3 & 1929-2004 & $\mathrm{P}, \mathrm{T}$ \\
\hline
\end{tabular}


graphy Mission and land cover data sets derived from the Forest Resources Inventory of Manitoba. The initial model parameters, including evaporation coefficients, soil properties (infiltration capacity and wilting point), snowmelt rates, and albedo (surface and snow) were estimated based on the literature. The Burntwood and the Taylor River basins were respectively divided into 11 and 7 ASAs, with 7 land cover types for each: coniferous forest, deciduous forest, mixed forest, muskeg, impervious, water, and marsh. For convenience, the SLURP model that was set up for the Taylor River basin is called the Taylor model and that for the Burntwood River basin is called the Burntwood model.

We used the meteorological data for the period 1970-2000 that were measured at the weather stations listed in Table 1. Data from stations with short periods were used to fill in missing records at Thompson A, The Pas A, Flin Flon A, and Island Falls. The data from the stations were spatially interpolated to the centroids of the basins by inverse squared distance weighting (ISDW). A drawback of this interpolation technique is that it tends to result in more wet days than observed at any individual station. However, when daily precipitation values below $0.5 \mathrm{~mm}$ were ignored, the number of wet days and total precipitation for the interpolated records were found to be quite similar to the station records. Therefore, the ISDW interpolation method is deemed acceptable for this study.

\subsection{Model calibration and validation}

Calibrated parameters for each model were directly adopted from St. Laurent \& Valeo (2007) where the detailed calibration and validation procedures are described. A summary is provided in this section.

Observed streamflow data were obtained for 2 hydrometric stations (Table 1) from the Water Survey of Canada website (www.wsc.ec.gc.ca/hydat/H2O/index e.cfm? cname=main_e.cfm) and used for calibration. The station named 'Taylor River near Thompson' (05TG002) was used to calibrate the Taylor model and the station named 'Burntwood River above Leaf Rapids' (05TE002) was used for the Burntwood model.

St. Laurent \& Valeo (2007) calibrated the Taylor model for the year 1996 by manually adjusting a number of parameters including maximum infiltration rate, retention constant for the fast store, maximum capacity of the fast store, retention constant for the slow store, maximum capacity of the slow store, rain/snow division temperature, canopy capacity, albedo, snowmelt rate, and evaporation related parameters such as wilting point and field capacity. The calibrated model was validated over the period 1985-2000 when streamflow data are available for both basins. The validated para- meters from the Taylor model were then applied as the initial parameter set for the Burntwood model. Because of the presence of many large lakes in the Burntwood River basin, some adjustments of ET parameters and routing coefficients were required (St. Laurent \& Valeo 2007).

To evaluate the performance of the calibrated models, we considered the deviation of runoff volume $\left(D_{V}\right)$, the Nash-Sutcliffe efficiency $(E)$, and the mean absolute error (MAE) of daily runoff series, defined respectively as:

$$
\begin{array}{r}
D_{V}(\%)=\frac{\bar{S}-\bar{O}}{\bar{O}} \times 100 \\
E=1-\frac{\sum\left(S_{i}-O_{i}\right)^{2}}{\sum\left(O_{i}-\bar{O}\right)^{2}} \\
\text { MAE }=\frac{\sum\left|S_{i}-O_{i}\right|}{N}
\end{array}
$$

where $S$ denotes the stream flow simulated by the model, $O$ the observed stream flow, and $N$ the number of daily records during the calibration and validation periods. An overbar indicates a mean value and $i$ is the daily time index. Each of the statistics measures volumetric error, goodness-of-fit, and daily average error between simulations and observations, respectively. The model is deemed perfect when $D_{V}$ is $0 \%, E$ is 1 , or MAE is 0 . Table 2 reports the validation statistics. The results from the Taylor and the Burntwood models are deemed reasonable, given the unavoidable limitations imposed by data quality and model structure. The $E$ value for Burntwood is somewhat lower than that for Taylor, which is a fact that can be attributed partly to SLURP's difficulty in modelling the hydrology of the large wetlands in the Burntwood River basin and partly to the lack of nearby weather stations with long-term data. Choi et al. (2009) obtained similar calibration statistics using the North American Regional Reanalysis data as input. Readers are referred to St. Laurent \& Valeo (2007) for final parameter values, annual validation statistics, and daily hydrographs between observations and simulations. Fig. 2 shows the observed and simulated variability of daily mean stream flow in the 2 basins during the validation period, which is not available in the reference. It is clear that the observed variability is greater than the simulated variability. The model performance is not as good with very high flows as with normal flows. The Taylor model produces an interquartile flow range that is similar to the observed, whereas the Burntwood model produces a somewhat narrower interquartile flow range than the observed. 
Table 2. SLURP (Semi-distributed Land Use-based Runoff Processes) model performance during the validation period (1985-2000). Missing records in the observation and the corresponding values in the simulation were excluded for calculation on a daily basis, resulting in slightly different $E$ values from those of St. Laurent \& Valeo (2007). $D_{V}$ : deviation of runoff volume, $E$ : Nash-Sutcliffe efficiency of daily runoff series, MAE: mean absolute error of daily runoff series

\begin{tabular}{|lcr|}
\hline & Taylor & Burntwood \\
\hline Simulated mean runoff $\left(\mathrm{m}^{3} \mathrm{~s}^{-1}\right)$ & 4.33 & 22.04 \\
$D_{V}(\%)$ & 1.08 & -0.89 \\
$E$ & 0.63 & 0.47 \\
MAE $\left(\mathrm{m}^{3} \mathrm{~s}^{-1}\right)$ & 1.90 & 10.41 \\
\hline
\end{tabular}

\section{CLIMATE SCENARIOS}

\subsection{Climate models and scenarios}

Climate scenarios were created based on the GCM simulations by the UK Hadley Centre and the Canadian Centre for Climate Modelling and Analysis (CCCMA) under 2 different greenhouse gas (GHG) emission scenarios named A2 and B2 (Nakicenovic \& Swart 2000). The Hadley Centre GCM (HadCM3) output has a horizontal resolution of $3.75^{\circ}$ longitude and $2.5^{\circ}$ latitude and was obtained from the Intergovernmental Panel on Climate Change (IPCC) Data Distribution Centre (DDC) 'TAR (Third Assessment Report) GCM data' page (www.mad.zmaw.de/IPCC_DDC/html/SRES_TAR/index. $\mathrm{html}$ ). The output from the second-generation Canadian Coupled General Circulation Model (CGCM2) under the B2 emission scenario has a horizontal resolution of
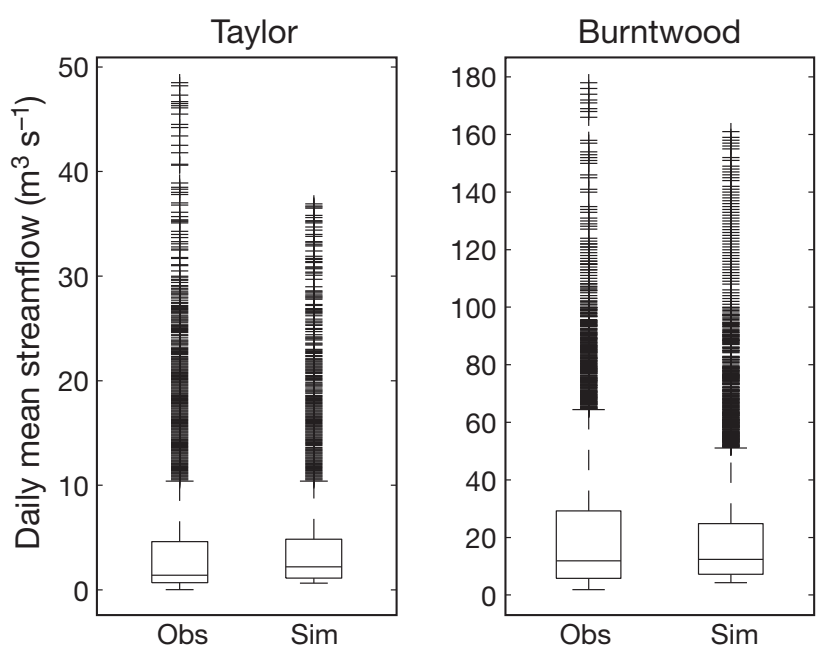

Fig. 2. Box plots of observed and simulated daily mean stream flow during the validation period. The boxes have lines at the lower quartile, median, and upper quartile values. Whiskers extend from each end of the box to the most extreme values within $1.5 \times$ the interquartile range. $(+)$ Outliers roughly $3.75^{\circ}$ longitude/latitude. It was also obtained from the IPCC DDC 'TAR GCM data' page. The output from the third-generation CGCM (CGCM3) simulation under the A2 emission scenario with the T47 resolution (roughly $3.75^{\circ}$ longitude/latitude) was obtained from the CCCMA website (www.cccma.bc.ec.gc.ca/ data/cgcm $3 / \mathrm{cgcm} 3 . \mathrm{shtml})$. The CGCM3 simulation was conducted for the IPCC Fourth Assessment Report (AR4) (www.mad.zmaw.de/IPCC_DDC/html/SRES_AR4/index. html) but not with the B2 scenario. All the models with respective scenarios project moderate increases in temperature compared to other GCMs for TAR (Cubasch et al. 2001) or AR4 (Meehl et al. 2007). Töyrä et al. (2005) report that HadCM3 is one of the models that best reproduce the observed climate in the Canadian Prairies provinces, whereas the CGCM2 is not so good in that respect. Both HadCM3 and CGCM2 project moderate annual temperature and precipitation changes in the future for the Canadian Prairies. Therefore, it should be kept in mind that the scenarios for this study represent cases of fairly moderate climate change.

The GCM output was obtained from 4 GCM grid points surrounding the basins and linearly interpolated for each basin for 3 different periods: 1971-2000, 2041-2070, and 2071-2099. The period 1971-2000 represents the control condition, and the other 2 represent future conditions. The combinations of time slices, emission scenarios, and GCMs are named and listed in Table 3. For example, Scenario H1A denotes the climate condition for the period 2041-2070, simulated by HadCM3 under the A2 emission scenario.

\subsection{Changes in temperature and precipitation simulated by GCMs}

Fig. 3 shows the projected changes in mean annual temperature and precipitation for the Burntwood River basin. Those for the Taylor River basin are similar and thus not shown. The 2 GCMs consistently project warmer and wetter climates. The CGCM projects more

Table 3. Climate scenarios and associated time slice, emission scenario, and global climate models (GCM)

\begin{tabular}{|lccc|}
\hline Scenario name & Time slice & Emission scenario & GCM \\
\hline H1A & $2041-2070$ & A2 & HadCM3 \\
H2A & $2071-2099$ & A2 & HadCM3 \\
C1A & $2041-2070$ & A2 & CGCM3 \\
C2A & $2071-2099$ & A2 & CGCM3 \\
H1B & $2041-2070$ & B2 & HadCM3 \\
H2B & $2071-2099$ & B2 & HadCM3 \\
C1B & $2041-2070$ & B2 & CGCM2 \\
C2B & $2071-2099$ & B2 & CGCM2 \\
\hline
\end{tabular}




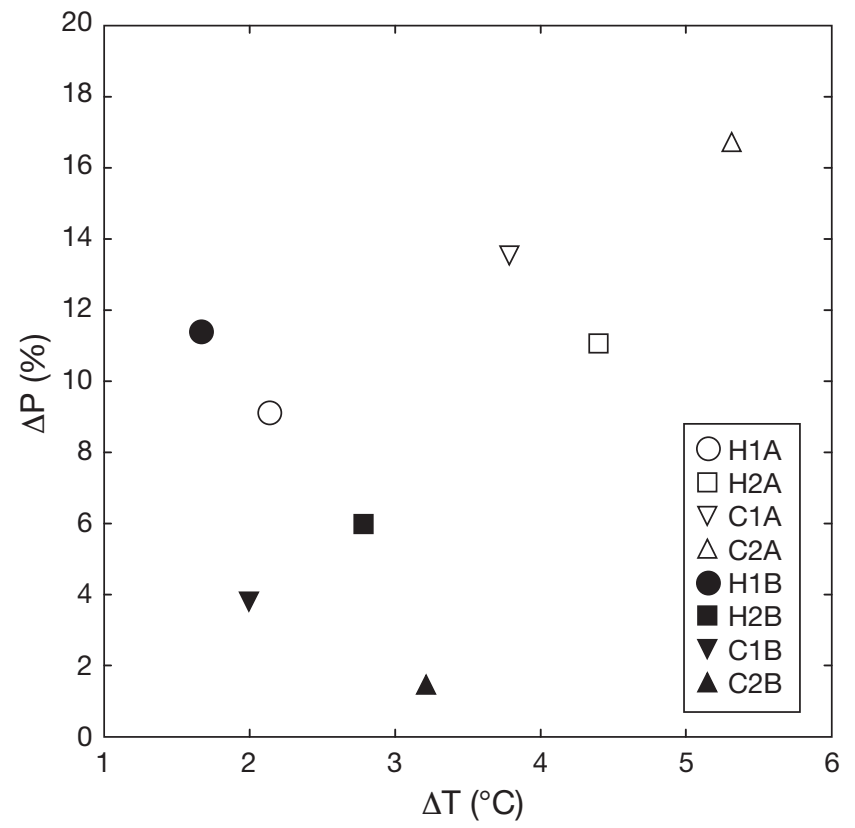

Fig. 3. Projected changes in mean annual temperature $(\Delta \mathrm{T})$ and precipitation $(\Delta \mathrm{P})$ under different climate scenarios with respect to the 1971-2000 mean for the Burntwood River basin

warming than the HadCM3 under both scenarios. The models agree that 2071-2099 will be warmer than 2041-2070. Under the A2 scenario, precipitation is expected to increase throughout the next century. Under the B2 scenario, precipitation will increase with greater magnitude during 2041-2070 than 2071-2099. The precipitation amount occurring on days with mean temperature below $0^{\circ} \mathrm{C}$ is not projected to change sig- nificantly on an annual basis (not shown in the graph).

Monthly changes in climate variables for the Taylor River basin are presented in Fig. 4 (results for Burntwood are similar). The graphs reveal significant month-to-month and model-to-model variation in the amplitude of the climate change signal. CGCM3 projects substantial winter warming under the A2 scenario while HadCM3 projects more consistent temperature increases throughout the year. Precipitation is projected to increase with large percentage points during spring months (and in winter months in some cases) and increase with small percentage points (or decrease in some cases) during summer or early autumn. Most of the additional winter precipitation comes as snow while the increased spring precipitation is a mixture of rain and snow. The difference between the 2 basin locations is negligible because the distance between them is short compared to the GCM grid spacing. HadCM3 projects the greatest warming in summer or early autumn.

\subsection{Scenario time series for hydrological modelling}

The mean monthly temperature and precipitation changes simulated by the GCMs were converted to daily time series for SLURP simulations by the socalled 'delta' method or climate change factor method (Diaz-Nieto \& Wilby 2005). The standard approach for the delta method is that the GCM-simulated difference for each calendar month (absolute difference for temperature and relative difference for precipitation) between a future period and the control period is
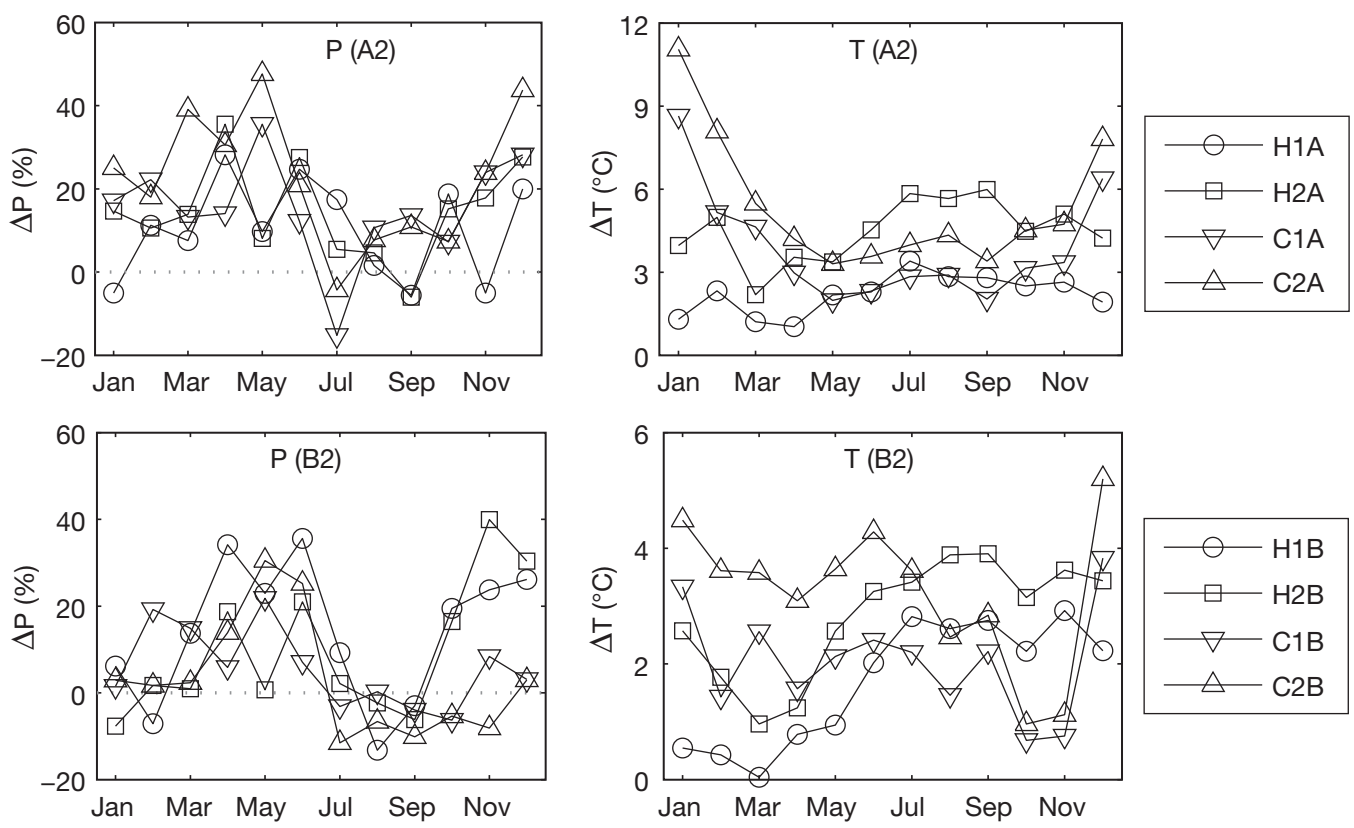

Fig. 4. Changes in the 30 yr mean monthly precipitation $(\mathrm{P})$ and temperature $(\mathrm{T})$ under different climate scenarios with respect to the 1971-2000 mean for the Taylor River basin 
determined and then superimposed on the historical daily temperature and precipitation series. The delta method is a simple, yet widely used method (e.g. Bouraoui et al. 2002, Stone et al. 2003, Wilby \& Harris 2006, Graham et al. 2007) to create scenario time series from GCM output. Daily time series were generated for each of the climate scenarios listed in Table 3.

A drawback of the delta method in its standard form is that it does not allow for possible changes in variability to be taken into account. It has been argued that changes in variability may in some cases be as important as changes in means when evaluating the impact of climate change. The inadequacy of the delta method to take into account the changed variability was addressed by modifying the equation for the delta method based on the method introduced by Leander \& Buishand (2007). The historical daily precipitation amount $P$ was transformed to the future amount $P^{*}$ using

$$
P^{*}=\alpha P^{\beta}
$$

In the standard delta method, $\beta$ is unity, and $\alpha$ is the ratio of the averaged future precipitation to the averaged control precipitation, both of which are simulated by the GCM. In the modified method, the parameters $\alpha$ and $\beta$ were determined by numerical optimisation as the values that produced the following mean and standard deviation (SD) of $P^{*}$ :

$$
\begin{gathered}
\bar{P}^{*}=\bar{P} \times \frac{\bar{P}_{f}}{\bar{P}_{c}} \\
\sigma\left(P^{*}\right)=\sigma(P) \times \frac{\sigma\left(P_{f}\right)}{\sigma\left(P_{C}\right)}
\end{gathered}
$$

where $P_{f}$ is the daily precipitation series from the future GCM run and $P_{C}$ is the daily precipitation from the control GCM run. $\sigma$ denotes the SD and an overbar denotes the average over the corresponding period. The MATLAB function 'fminsearch' was used for optimisation using the initial values of $\bar{P}_{f} / \bar{P}_{C}$ and unity for $\alpha$ and $\beta$, respectively.

For temperature, the transformation was made using

$$
T^{*}=\bar{T}+\frac{\sigma\left(T_{f}\right)}{\sigma\left(T_{C}\right)}(T-\bar{T})+\bar{T}_{f}-\bar{T}_{C}
$$

where $T_{f}$ is the daily temperature series from the future GCM run and $T_{C}$ is the daily temperature series from the control GCM run. In the standard delta method, the first 2 terms on the right side of the equation are simply $T$, and $\bar{T}_{f}-\bar{T}_{C}$ is $\Delta T$. The transformation was made separately for each calendar month both for precipitation and temperature. This method was applied only to the output from CGCM3 under the A2 scenario (Scenarios C1A and C2A) due to the limited availability of daily GCM data. For other GCM and emission scenario combinations, the conventional method was used.
The effect of the modified delta method on the variability of future temperature and precipitation for the period 2041-2070 is shown in Fig. 5. The effect on temperature is shown as the SD of mean monthly temperature. The modified delta method produced slightly different temperature results than the standard method, but the differences in this particular case are small. The effect on the variability of precipitation is shown as CVs. As can be seen from Fig. 5, the modified delta method produced mean monthly $\mathrm{CV}$ values that were higher than those obtained with the standard delta method in every calendar month except July. It should be noted that the standard delta method does not allow for changes in the CV of the historical precipitation.

The distribution of daily precipitation values shows that the median is greater with the standard method ( 0.19 vs. 0.11 for the modified method) but the maximum (56.8 for the standard vs. 83.0 for the modified method) and the 95th percentile ( 7.96 for the standard vs. 8.03 for the modified method) are greater with the modified method. The 95th percentiles are very similar but there is a large difference in the maximum, suggesting that the effect of the modified method is most prominent during intense precipitation events.

\section{RESULTS}

The calibrated SLURP model for each river basin was run with the historical 1970-2000 meteorological data. These runs represent the current hydrological regime and are subsequently referred to as the control runs (Con).

The control runs were followed by scenario runs where SLURP was forced with perturbed input data. The scenario runs were made in 3 ways depending on the method of perturbing the input data. (1) Each of the historical temperature and precipitation data sets was perturbed in incremental steps to investigate the model's sensitivity to changes in meteorological input. (2) The control input data were perturbed using the standard delta method for each climate scenario listed in Table 3 to investigate the response to GCM-driven climate scenarios. The most comprehensive runs and analyses were made with the standard delta method. (3) The control input data were perturbed using the modified delta method and the results were compared with those from the standard delta method. The purpose was to evaluate the effect of the changed variability of future temperature and precipitation relative to the standard method. Results from the scenario runs are presented in the following. The result for the first simulation year in each run was not included in the analysis since the model needs a warm-up period. 

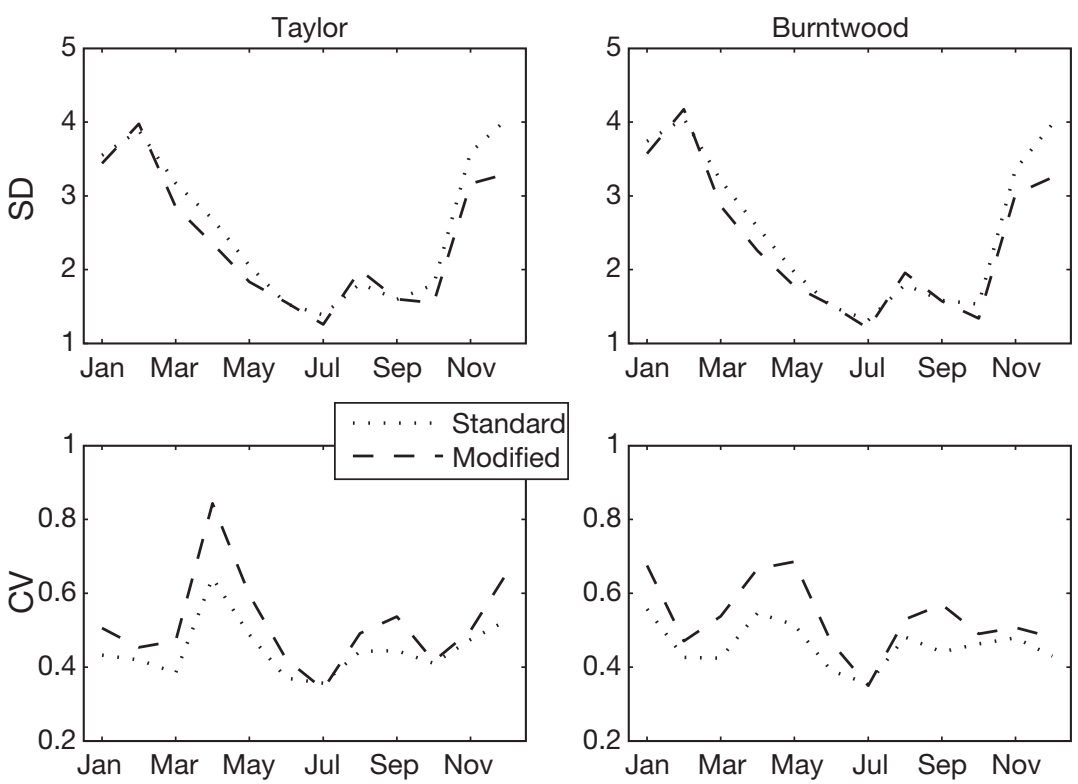

Fig. 5. Standard deviation (SD) of mean monthly temperature (top) and coefficient of variation (CV) of mean monthly precipitation (bottom) for the Taylor and the Burntwood River basins. Standard denotes the result from the standard delta method and Modified denotes result from the modified delta method. Period: 2041-2070

\subsection{Runoff changes from incremental perturbations to input data}

To investigate the model's sensitivity to changes in meteorological input, observed temperature and precipitation series were arbitrarily changed by a fixed amount and applied to the model. The temperature series was changed by $-2,+2,+4,+6,+8$, and $+10^{\circ} \mathrm{C}$ throughout the period while all other input variables were held constant; the precipitation series was changed by $-20,-15,-10,-5,+5,+10,+15$, and $+20 \%$, again with all the other input variables unchanged. Corresponding changes in runoff are presented in Fig. 6 only for Taylor as the results for Burntwood are fairly similar.

Fig. 6A indicates that the model is fairly insensitive to changes in daily temperature when the output is averaged over the year (left graph). The magnitude of the changes is only 0 to $3 \%$. Temperature changes affect runoff mostly through snow accumulation, snowmelt, and ET. Rising temperatures result in less snow accumulation and earlier start of snowmelt but also in more ET (these different effects on runoff are manifested in the right-hand graph). Runoff during the March-May period increases from 53 (control) to $65 \mathrm{~mm}$ with rising temperatures $\left(+10^{\circ} \mathrm{C}\right)$. On the other hand, summer runoff (June-August) decreases from 54 (control) to $33 \mathrm{~mm}\left(+10^{\circ} \mathrm{C}\right)$. The summer runoff decrease is due not only to enhanced ET but also to earlier recession of snowmelt runoff.
The model's sensitivity to precipitation changes is summarised in Fig. 6B. The change in mean annual runoff is essentially linearly related to precipitation changes; this result agrees with other studies using a similar approach (e.g. Sharma et al. 2000, Frei et al. 2002). The percentage of runoff change exceeds that of precipitation change, indicating that effective precipitation (precipitation - actual evaporation) increases with increased precipitation. Runoff change is more prominent during summer than during winter. Summer is a season with high precipitation and low runoff in this region. Therefore, a large percentage increase in precipitation in the summer yields a larger absolute precipitation increase than in other months, which contributes to increases both in runoff and ET. During winter, increased precipitation falls as snow, which does not immediately contribute to runoff. However, the enhanced soil moisture condition year-round leads to higher base flow during winter.

\subsection{Runoff changes from the standard delta method}

Relative changes in median annual runoff under different climate scenarios produced using the standard delta method are summarised in Table 4 . The results demonstrate the hydrological response to the changes in the means of temperature and precipitation simulated by GCMs. The runoff in both river basins is projected to increase in all scenarios except in $\mathrm{C} 2 \mathrm{~B}$, and the changes are statistically significant (at $\alpha=0.05$ ) in 4 scenarios (H2A, C1A, C2A, and H1B). CGCM projects significantly larger runoff increases under the A2 emission scenario (scenarios $\mathrm{C} 1 \mathrm{~A}$ and $\mathrm{C} 2 \mathrm{~A}$ ) than under B2 (C1B and C2B), while HadCM3 (H1A and H2A vs. H1B and H2B) projects similar increases ( 20\%) under both emission scenarios. All the models project larger increases during 2071-2099 (H2A and C2A) than during 2041-2070 (H1A and C1A) under the A2 emission scenario. Under the B2 scenario, the magnitude of increases is smaller during 2071-2099 (H2B and C2B) than during 2041-2070 (H1B and C1B).

Projected changes in mean monthly runoff are presented in Fig. 7. Large increases are expected in April with all GCMs and all scenarios. Both HadCM3 and CGCM project precipitation and temperature increases in April and May. The precipitation increase combined with earlier onset of snowmelt explains this increase. Summer runoff is predicted to decrease in 

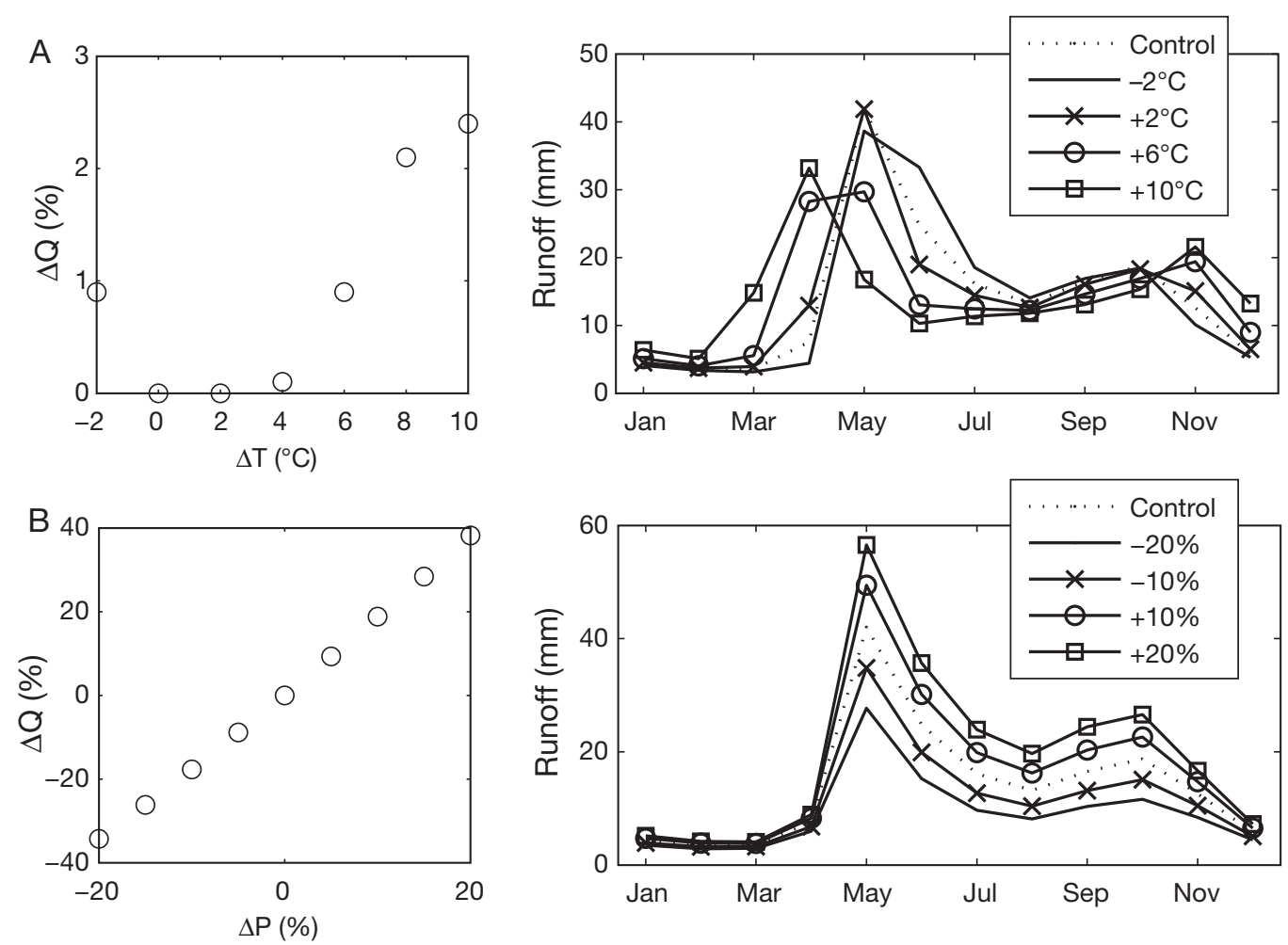

Fig. 6. Mean annual (left) and monthly (right) runoff changes $(\Delta Q)$ in the Taylor River basin in response to incremental temperature (A) and precipitation (B) changes

several scenarios, partly due to the time-shift in the spring freshet recession curve. Currently, the mean monthly runoff is highest in May and remains highest in this month in the future with every scenario. The large runoff increase in November and December is due to increased precipitation and a higher rainfall: snow ratio.

Sushama et al. (2006) reported similar results for the Churchill and the Nelson River basins based on simulations using the Canadian Regional Climate Model (CRCM) conditioned by CGCM2 with the A2 and IS92a scenarios. Earlier start of spring snowmelt and increased winter runoff were simulated for the Nelson River, which is consistent with the present study. However, CRCM simulated the highest monthly runoff in either June (v3.6) or April (v3.7) for the current climate for Nelson. A major difference in future projections from the present study is that both CRCM versions simulated slight decreases in spring peak flow and did not simulate a noticeable increase in late-autumn runoff. For the Churchill River basin, CRCM simulated a small increase in late-autumn and winter runoff, as well as a large increase in the month prior to the peak month. The change in snowmelt peak depends on the model version.

Overall, the mean monthly hydrograph from the CRCM simulations for Churchill looks more similar to that in the present study than that for Nelson. Most likely, the 2 main reasons for the different timing of peak flows in the present study and in Sushama et al. are: (1) CRCM has biases in simulating the current climate. Version 3.6 in particular significantly overestimates summer precipitation for both basins and underestimates snow-water equivalent for Churchill. (2) Sushama et al. could not validate the CRCM-simulated stream flow against the observed stream flow because the Nelson and the Churchill River basins are highly regulated and the observed hydrographs are fairly flat. The modelling sites in the present study were carefully chosen to avoid regulated basins.

In addition to annual and seasonal runoff, we also analysed low and high flow statistics. We defined low and high flows as any daily flows below or above predetermined thresholds. Daily flows below the flow

Table 4. Relative changes in median annual runoff from scenario runs with respect to the control runs for the Taylor and the Burntwood River basins. * Significant $(\alpha=0.05)$

\begin{tabular}{|lcccccccc|}
\hline \multicolumn{10}{|c|}{ Runoff change (\%) } \\
& H1A & H2A & C1A & C2A & H1B & H2B & C1B & C2B \\
\hline Taylor & 17.6 & $23.4^{*}$ & $23.2^{*}$ & $33.6^{*}$ & $21.3^{*}$ & 16.3 & 6.1 & -0.2 \\
Burntwood & 20.0 & $31.6^{*}$ & $34.4^{*}$ & $42.9^{*}$ & $29.2^{*}$ & 17.3 & 8.8 & 4.5 \\
\hline
\end{tabular}



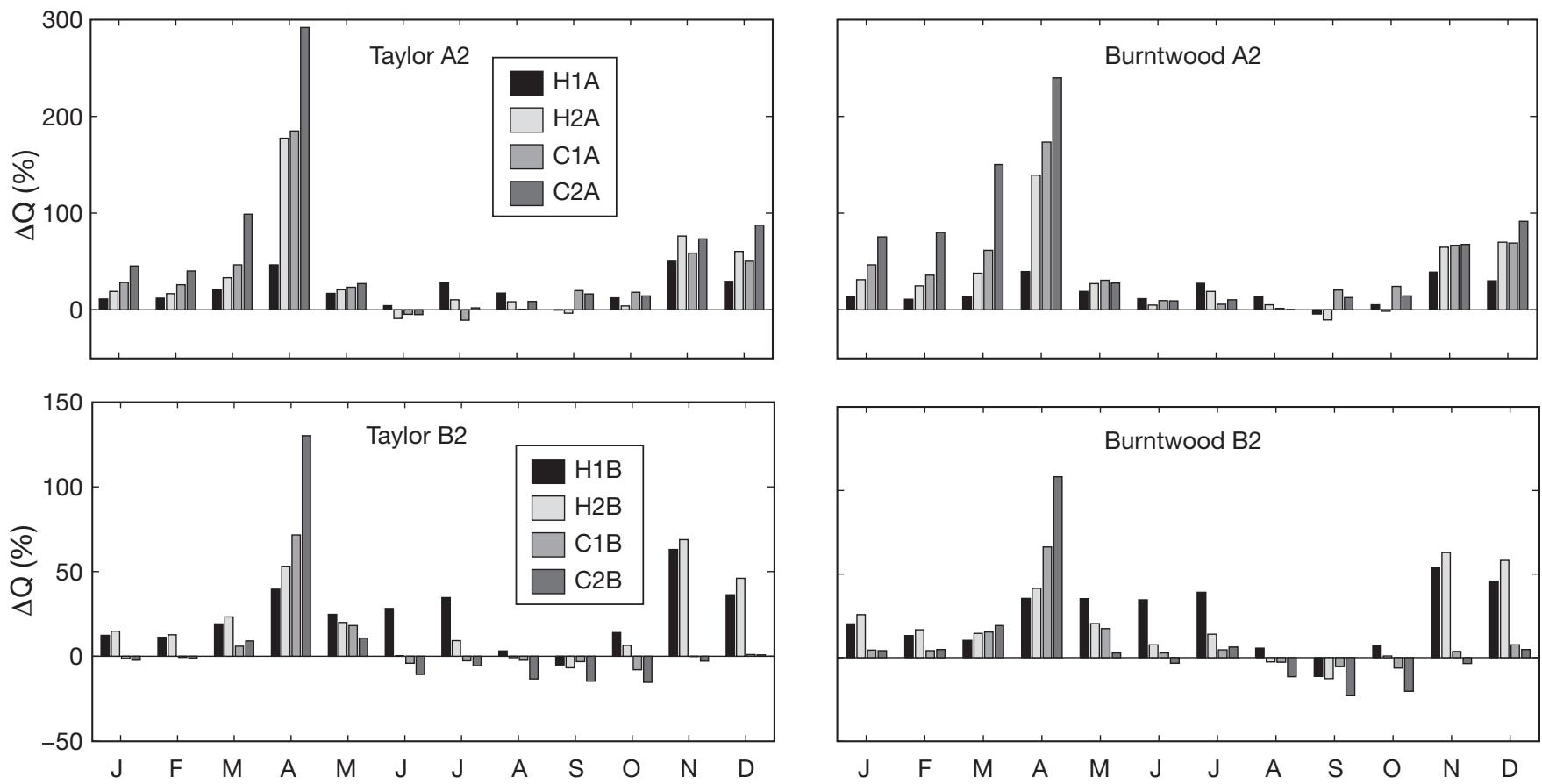

Fig. 7. Mean monthly runoff changes $(\Delta \mathrm{Q})$ from scenario runs with respect to runoff from control runs

value exceeded by $80 \%$ of all values (Q80) during the 30 yr control period were regarded as low flows. The threshold for high flows was set at the flow value exceeded by $20 \%$ of all values (Q20) from the control run. The thresholds were chosen to make the results comparable to those from Sushama et al. (2006). The frequency of extreme flows was calculated as the number of days below or above the threshold values for each year during each $30 \mathrm{yr}$ simulation period. The control Q80 daily flows are $1.3 \mathrm{~m}^{3} \mathrm{~s}^{-1}\left(0.12 \mathrm{~mm} \mathrm{~d}^{-1}\right)$ and $7.2 \mathrm{~m}^{3} \mathrm{~s}^{-1}\left(0.11 \mathrm{~mm} \mathrm{~d}^{-1}\right)$ for Taylor and Burntwood, respectively, whereas the respective control Q20 daily flows are $7.0 \mathrm{~m}^{3} \mathrm{~s}^{-1}\left(0.68 \mathrm{~mm} \mathrm{~d}^{-1}\right)$ and $33.2 \mathrm{~m}^{3} \mathrm{~s}^{-1}$ $\left(0.49 \mathrm{~mm} \mathrm{~d}^{-1}\right)$.

The number of days with mean flow below the corresponding threshold under different scenarios is presented in Fig. 8A as box plots. Under the A2 scenario, the median frequency of annual low flows in both basins is predicted to decrease significantly ( $\alpha=0.05$ ). The decrease is more substantial with CGCM and in the farther future. Under the B2 scenario, the changes in the median frequency are significant with HadCM3 but not with CGCM $(\alpha=0.05)$.

The frequency of high flows from different runs is presented in Fig. 8B. Under the A2 scenario, the median frequency is predicted to increase in every run but the difference is statistically significant $(\alpha=0.05)$ only with the $\mathrm{C} 1 \mathrm{~A}$ and $\mathrm{C} 2 \mathrm{~A}$ scenarios in the 2 basins. Q20 is predicted to increase to $9.6 \mathrm{~m}^{3} \mathrm{~s}^{-1}$ for Taylor and $49.1 \mathrm{~m}^{3} \mathrm{~s}^{-1}$ for Burntwood in the C2A scenario. On the other hand, under the B2 scenario, the increase in the median frequency is statistically significant only with the H1B run for Taylor. Other scenarios still predict increases except with C2B for Taylor.

Sushama et al. (2006) obtained similar results for the Churchill and the Nelson River basins both for low and high flows. The median number of days per year with mean daily flow below the control Q80 was predicted to significantly decrease at $\alpha=0.05$ both for the Churchill and the Nelson River basins under the A2 scenario. The range of the data expanded to a much greater extent than in the present study, which might be partially attributed to the ability of a RCM to change the variability of climate data. Sushama et al. reported mixed results for the frequency of high flows. The frequency increased or decreased depending on scenarios, model versions and river basins, and the changes were not statistically significant. In both studies, the changes in the frequency of high flows are less consistent and less significant than the changes in low flows.

Fig. 9 shows the cumulative probability distribution function $(\mathrm{F}(\mathrm{x}))$ of the simulated daily runoff series under different scenarios, with focus on Q20 ( $\mathrm{F}(\mathrm{x})=$ $0.8)$ and $\mathrm{Q} 80(\mathrm{~F}(\mathrm{x})=0.2)$ daily flows. A2 emission scenarios generally result in larger increases in Q80 and Q20 than B2 scenarios, which is consistent with the frequency of high and low flows in Fig. 8. The values of Q80 (measured in $\mathrm{mm} \mathrm{d}^{-1}$ ) are fairly similar in both basins, but Q20 values are much greater in Taylor than in Burntwood, indicating larger variability in stream 

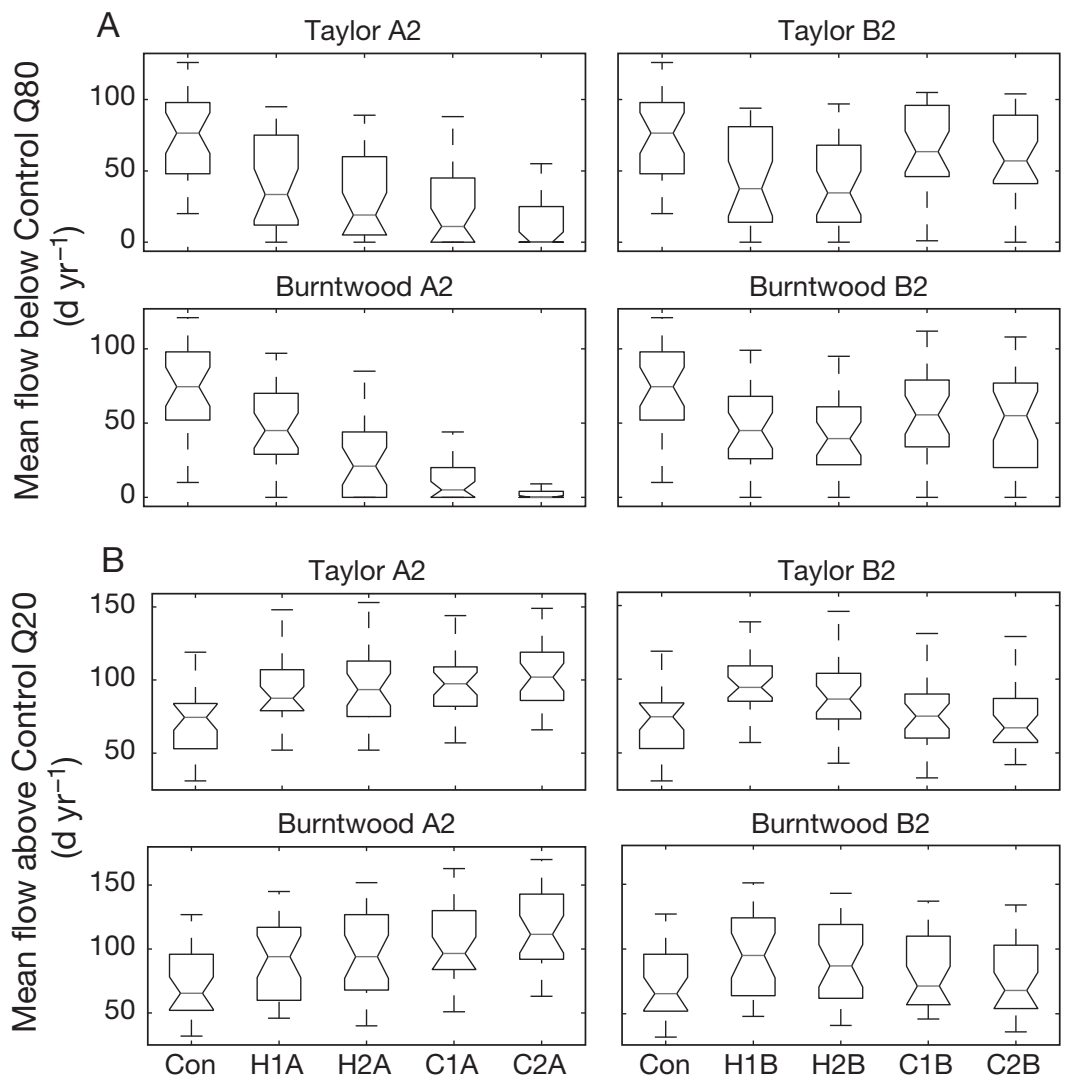

Burntwood B2

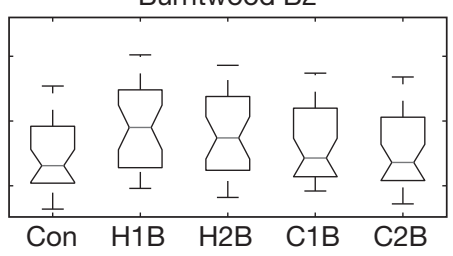

Scenario

Fig. 8. Box plots of the number of days per year with mean flow below Control Q80 (A) and above Control Q20 (B). The boxes have lines at the lower quartile, median, and upper quartile values. Whiskers extend from each end of the box to the most extreme values within $1.5 \times$ the interquartile range

\subsection{Runoff changes from the modified delta method}

Table 5 presents the mean annual runoff (MAR), Q20 and Q80 daily flows from the scenario runs with the standard and the modified delta methods for CGCM3-A2. The modified delta method takes into account the changes in the variability of temperature and precipitation obtained from daily GCM output. It is clear that the runs with the modified delta method result in moderately higher runoff than those with the standard delta method for the same mean annual precipitation amount. Q20 daily flow is consistently higher and Q80 daily flow is consistently lower with the modified method. This is largely attributable to the increased variability in daily precipitation amounts. A comparison of the daily precipitation obtained with the modified and the standard delta methods reveals that they result in remarkably different distributions, with large day-today differences (both positive and negative) between them. The modified delta method produces more days with intense precipitation than the standard method, and the strong effect of intense precipitation on runoff leads to larger MAR with the modified method.

The mean monthly runoff from the flow in the former than in the latter. For Q80 daily flow, more divergence is observed between simulations with the A2 than with the B2 emission scenarios. Examination of the variability of mean daily precipitation and mean daily runoff indicates that they do not necessarily change in the same direction between scenarios, which may be attributed to the variability in temperature that affects snowmelt and ET.

In summary, Sushama et al. (2006) obtained results that are reasonably similar to those in this study despite several methodological differences: (1) they used a RCM conditioned by CGCM2 under the A2 scenario, while this study combined CGCM3 and A2; (2) their spatial domain is much greater than that in the present study; (3) we adopted an offline modelling approach while they used a coupled regional modelling system. In a practical sense, it is difficult to determine which approach would produce better results. As Fowler et al. (2007) reported, no examination of whether on- or off-line approaches produce better estimates of future impacts of climate change has been made. scenario runs with the standard and the modified delta methods is shown in Fig. 10, along with the control runs. Runoff is generally higher from spring through autumn with the modified delta method, primarily due to large increases in precipitation variability during the period, especially in April, May and September. The difference between the 2 methods is more pronounced for the period 2071-2099 than for 2041-2070.

\section{DISCUSSION AND CONCLUSIONS}

The simulation results reported in the previous section indicate that there is a wide range of possible changes in runoff characteristics for the basins studied here. However, in the majority of cases, the signals point in the same direction. Mean annual runoff is projected to increase in both basins with all emission scenarios and all GCMs. This direction of change also applies to high and low flow quantiles. While it is possible that other combinations of GCM and emissions scenarios could result in signals in the opposite direc- 

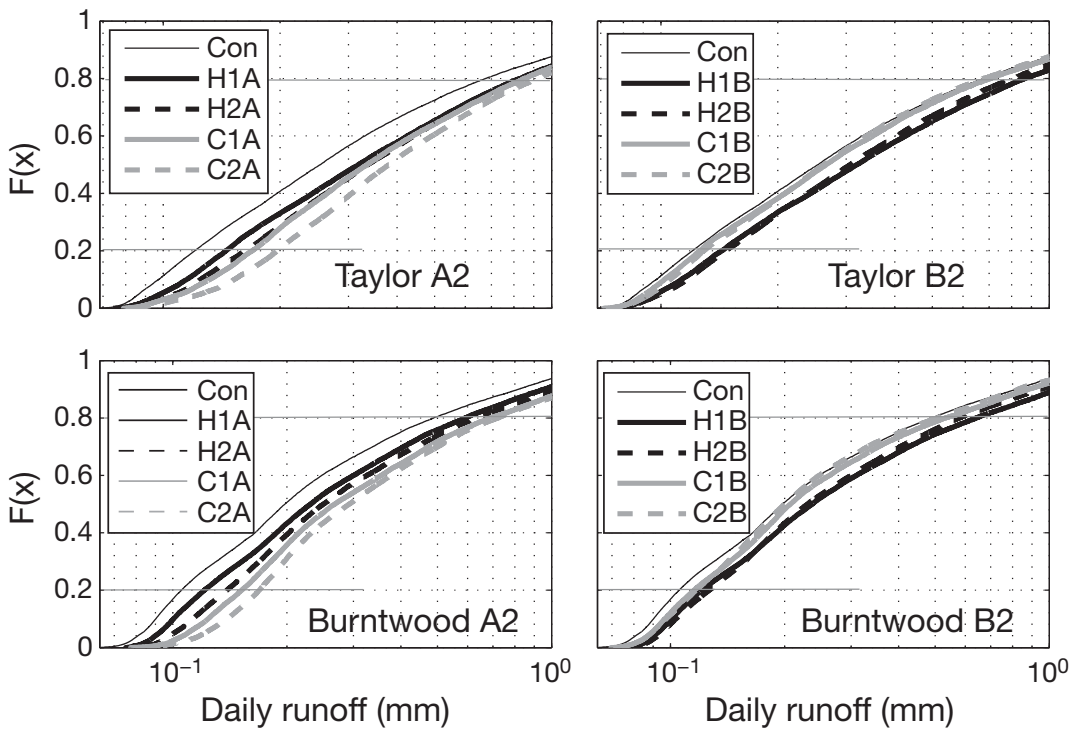

Fig. 9. Cumulative distribution function $(F(x))$ plots for daily runoff $(\mathrm{mm})$ from each scenario run. The graphs are truncated at a runoff of $1 \mathrm{~mm}$
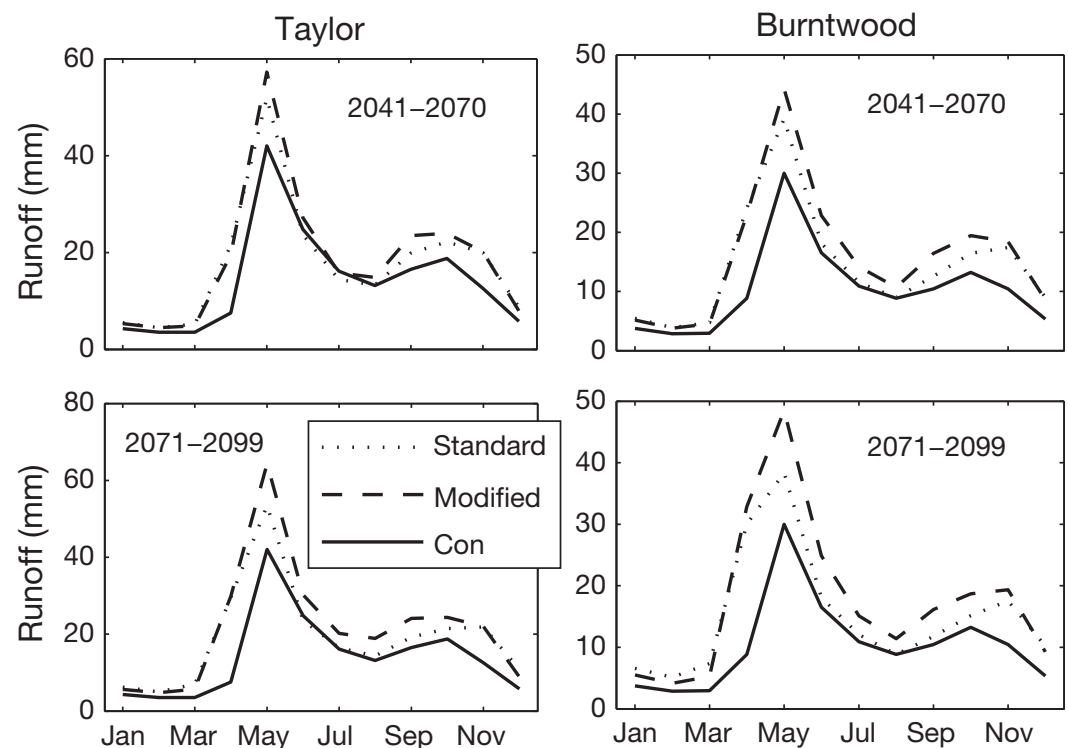

Fig. 10. Mean monthly runoff from scenario runs with the standard and the modified delta methods and from control runs (Con) tion, the consistent results from the present study and from Sushama et al. (2006) provide reasonable confidence. On the other hand, the results for summer and autumn runoff are not consistent between scenarios, mostly due to different precipitation projections.

The investigation of the modified delta method revealed the importance of considering the change in the $\mathrm{CV}$ of future precipitation. This change is ignored in the standard delta method, but, as the study showed, the 2 methods resulted in different runoff amounts. However, the seasonal runoff pattern obtained from both methods remains largely the same, and the increased runoff magnitudes from the modified method do not dramatically affect the conclusions obtained from the standard method. A drawback of the modified delta method is that it requires daily GCM data which are not as widely available as monthly summary statistics. Both methods are incapable of incorporating changes in the frequency and duration of precipitation events.

A couple of limitations of our analysis should be mentioned. First, the effects of possible vegetation changes associated with climate change have not been addressed. Currently muskeg and coniferous forest are the most dominant land cover types in the studied basins, but there is no guarantee that they will still prevail in a warmer and wetter climate. Therefore, the hydrological model may need a recalibration under different land cover conditions. Unfortunately, the classical simulation approach to climate change impact assessment on water resources is not capable of addressing this

Table 5. Mean annual runoff (MAR), high flows set at the flow value exceeded by $20 \%$ of all values during each simulation period (Q20), and low flow set at the flow value exceeded by $80 \%$ of all values during each simulation period (Q80) from control and scenario runs with the standard and the modified delta methods for CGCM3-A2. The results for 1971-2000 were produced using the measured meteorological station data, and are thus the same for standard and modified methods

\begin{tabular}{|c|c|c|c|c|c|c|c|c|c|}
\hline \multirow{3}{*}{ Taylor } & \multirow{2}{*}{$\overline{1971-2000}$} & \multirow{2}{*}{$\begin{array}{l}\text {-MAR (mm) } \\
2041-2070\end{array}$} & \multirow{2}{*}{ 2071-2099 } & \multicolumn{2}{|c|}{- Q20 $\left(\mathrm{m}^{3} \mathrm{~s}^{-1}\right)$} & $\overline{0071}$ & \multicolumn{2}{|c|}{$\longrightarrow \mathrm{Q} 80\left(\mathrm{~m}^{3} \mathrm{~s}^{-1}\right)$} & \multirow{2}{*}{$\overline{2071-2099}$} \\
\hline & & & & $1971-2000$ & $2041-2070$ & 2071-2099 & $1971-2000$ & $2041-2070$ & \\
\hline & & & & & & & & & \\
\hline Standard & 168.7 & 210.6 & 229.0 & 7.0 & 8.8 & 9.6 & 1.3 & 1.8 & 2.1 \\
\hline Modified & 168.7 & 224.9 & 259.1 & 7.0 & 9.7 & 11.1 & 1.3 & 1.7 & 1.9 \\
\hline Burntwood & & & & & & & & & \\
\hline Standard & 124.1 & 171.5 & 181.0 & 33.2 & 46.9 & 49.1 & 7.2 & 10.3 & 11.5 \\
\hline Modified & 124.1 & 191.3 & 211.1 & 33.2 & 54.0 & 60.5 & 7.2 & 10.0 & 10.9 \\
\hline
\end{tabular}


problem (Horton et al. 2006) and the present study is not an exception. Second, only one type of statistical downscaling method (the delta method) was used. Even though the delta method is simple and widely used, it has the major drawback of not reflecting changes in the frequency and duration of precipitation events in the future. Diaz-Nieto \& Wilby (2005) reported that flow changes based on the regression-based statistical downscaling method SDSM were generally more conservative and less consistent than those from the delta method. Wilby \& Harris (2006) obtained a much simpler cumulative distribution function for future changes in Q95 from the delta method than from SDSM. While a fair amount of criticism has rightfully been directed towards the delta method, it is important to realise that all downscaling methods have shortcomings. Compared to more sophisticated statistical downscaling methods, the delta method excels in at least one aspect: It is generally more transparent and the results derived from it are usually easier to interpret. While the development of statistical downscaling methods is an area of active research, the delta method will at least for some time continue to be a practical and useful method of climate change assessment.

As a final remark, we emphasize that climate change scenarios such as those developed in this study are subject to uncertainties from a variety of sources. Four key sources are: (1) the uncertainty in future GHG concentrations; (2) the uncertainty in the GCM's general ability to simulate the Earth's climate system and its response to changed GHG concentrations; (3) the uncertainty in downscaling GCM output to local scale; and (4) the uncertainty in the hydrologic model. There are other sources of uncertainty that may or may not be important, such as future changes in land cover which are often ignored in climate change studies. Uncertainty is an inherent component of climate change studies and some quantification of uncertainties should be part of any future detailed study.

Acknowledgements. The authors gratefully acknowledge the financial support provided by Manitoba Hydro for a research project that resulted in this article. We especially thank M. St. Laurent for providing calibrated parameter sets for the SLURP model.

\section{LITERATURE CITED}

Barr AG, Kite GW, Granger R, Smith C (1997) Evaluating three evapotranspiration methods in the SLURP macroscale hydrological model. Hydrol Process 11:1685-1705

Boer GJ, Flato G, Ramsden D (2000) A transient climate change simulation with greenhouse gas and aerosol forcing: projected climate to the twenty-first century. Clim Dyn 16:427-450

Bouraoui F, Galbiati L, Bidoglio G (2002) Climate change impacts on nutrient loads in the Yorkshire Ouse catchment (UK). Hydrol Earth Syst Sci 6:197-209
Choi W, Kim SJ, Rasmussen PF, Moore AR (2009) Use of the North American Regional Reanalysis for hydrological modelling in Manitoba. Can Water Resour J 34:17-36

Cubasch U, Meehl GA, Boer GJ, Stouffer RJ and others (2001) Projections of future climate change. In: Houghton JT, Ding Y, Griggs DJ, Noguer $M$ and others (eds) Climate change 2001: the scientific basis. Cambridge University Press, Cambridge, p 525-582

Cunderlik JM, Simonovic SP (2005) Hydrological extremes in a southwestern Ontario river basin under future climate conditions. Hydrol Sci J 50:631-654

de Blij HJ, Muller PO (1996) Physical geography of the global environment. John Wiley, New York

> Diaz-Nieto J, Wilby RL (2005) A comparison of statistical downscaling and climate change factor methods: impacts on low flows in the River Thames, United Kingdom. Clim Change 69:245-268

Fowler HJ, Blenkinsop S, Tebaldi C (2007) Linking climate change modelling to impacts studies: recent advances in downscaling techniques for hydrological modelling. Int J Climatol 27:1547-1578

Frei A, Armstrong RL, Clark MP, Serreze MC (2002) Catskill Mountain water resources: vulnerability, hydroclimatology, and climate-change sensitivity. Ann Assoc Am Geogr 92:203-224

Graham LP, Andréasson J, Carlsson B (2007) Assessing climate change impacts on hydrology from an ensemble of regional climate models, model scales and linking methods-a case study on the Lule River basin. Clim Change 81:293-307

Haberlandt U, Kite GW (1998) Estimation of daily space-time precipitation series for macroscale hydrological modeling. Hydrol Process 12:1419-1432

Horton P, Schaefli B, Mezghani A, Hingray B, Musy A (2006) Assessment of climate-change impacts on alpine discharge regimes with climate model uncertainty. Hydrol Process 20:2091-2109

Johns TC, Gregory JM, Ingram WJ, Johnson CE and others (2003) Anthropogenic climate change for 1860 to 2100 simulated with the HadCM3 model under updated emissions scenarios. Clim Dyn 20:583-612

> Kite GW (1993) Application of a land class hydrological model to climatic change. Water Resour Res 29:2377-2384

> Kite GW (1995) Scaling of input data for macroscale hydrologic modeling. Water Resour Res 31:2769-2781

Kite G (2000) Manual for the SLURP Hydrological Model, V. 11.4. International Water Management Institute, Colombo

> Leander R, Buishand TA (2007) Resampling of regional climate model output for the simulation of extreme river flows. J Hydrol (Amst) 332:487-496

Leenders EE, Woo M-k (2002) Modeling a two-layer system at the subarctic, subalpine treeline during snowmelt. Water Resour Res 38:1202, doi:1210.1029/2001WR000375

Meehl GA, Stocker TF, Collins WD, Friedlingstein P and others (2007) Global climate projections. In: Solomon S, Qin D, Manning M, Chen Z and others (eds) Climate change 2007: the physical science basis. Contribution of Working Group I to the fourth assessment report of the Intergovernmental Panel on Climate Change. Cambridge University Press, Cambridge, p 747-845

> Merritt WS, Alila Y, Barton M, Taylor B, Cohen S, Neilsen D (2006) Hydrologic response to scenarios of climate change in sub watersheds of the Okanagan basin, British Columbia. J Hydrol (Amst) 326:79-108

Mesinger F, DiMego G, Kalnay E, Mitchell K and others (2006) North American regional reanalysis. Bull Am Meteorol Soc 87:343-360 
Metcalfe RA, Buttle JM (1999) Semi-distributed water balance dynamics in a small boreal forest basin. J Hydrol (Amst) 226:66-87

Nakicenovic N, Swart R (eds) (2000) Special report on emission scenarios. Cambridge University Press, Cambridge

Roy L, Leconte R, Brissette FP, Marche C (2001) The impact of climate change on seasonal floods of a southern Quebec River Basin. Hydrol Process 15:3167-3179

Sharma KP, Vorosmarty CJ, Moore B III (2000) Sensitivity of the Himalayan hydrology to land-use and climatic changes. Clim Change 47:117-139

Spittlehouse DL (1989) Estimating evapotranspiration from land surfaces in British Columbia. Estimation of areal evapotranspiration. IAHS Publications 177:245-253

St. Laurent ME, Valeo C (2007) Large-scale distributed watershed modelling for reservoir operations in cold boreal regions. Can J Civ Eng 34:525-538

Stone MC, Hotchkiss RH, Mearns LO (2003) Water yield responses to high and low spatial resolution climate change scenarios in the Missouri River Basin. Geophys Res Lett 30:1186, doi:1110.1029/2002GL016122

Su M, Stolte WJ, van der Kamp G (2000) Modelling Canadian prairie wetland hydrology using a semi-distributed streamflow model. Hydrol Process 14:2405-2422

Sushama L, Laprise R, Caya D, Frigon A, Slivitzky M (2006) Canadian RCM projected climate-change signal and its

Editorial responsibility: Balaji Rajagopalan,

Boulder, Colorado, USA sensitivity to model errors. Int J Climatol 26:2141-2159

The Manitoba Hydro-Electric Board (2006) The Manitoba Hydro-Electric Board 55th annual report for the year ended March 31, 2006. Winnipeg

> Thorne R, Woo Mk (2006) Efficacy of a hydrologic model in simulating discharge from a large mountainous catchment. J Hydrol (Amst) 330:301-312

Töyrä J, Pietroniro A, Bonsal B (2005) Evaluation of GCM simulated climate over the Canadian Prairie provinces. Can Water Resour J 30:245-262

> van der Linden S, Woo Mk (2003) Transferability of hydrological model parameters between basins in data-sparse areas, subarctic Canada. J Hydrol (Amst) 270:182-194

- Westmacott JR, Burn DH (1997) Climate change effects on the hydrologic regime within the Churchill-Nelson River Basin. J Hydrol (Amst) 202:263-279

Wilby RL, Harris I (2006) A framework for assessing uncertainties in climate change impacts: low-flow scenarios for the River Thames, UK. Water Resour Res 42:W02419, doi:10.1029/2005WR004065

- Woo Mk, Thorne R (2006) Snowmelt contribution to discharge from a large mountainous catchment in subarctic Canada. Hydrol Process 20:2129-2139

Yulianti JS, Burn DH (1998) Investigating links between climatic warming and low streamflow in the Prairies region of Canada. Can Water Resour J 23:45-60

Submitted: January 15, 2009; Accepted: August 5, 2009 Proofs received from author(s): October 21, 2009 